In Proceedings of The Seventh International Conference on Computational Structures Technology, Topping, B.H.V. and Mota Soares, C.A., Eds., Civil-Comp Press, Stirling, United Kingdom, 2004.

\title{
Reduced Order Methods for Prediction of Thermal-Acoustic Fatigue
}

\author{
A. Przekop $\dagger$ and S.A. Rizzi $†$ \\ † National Institute of Aerospace \\ Hampton, Virginia, United States of America \\ * Structural Acoustic Branch, NASA Langley Research Center \\ Hampton, Virginia, United States of America
}

\begin{abstract}
The goal of this investigation is to assess the quality of high-cycle-fatigue life estimation via a reduced order method, for structures undergoing random nonlinear vibrations in a presence of thermal loading. Modal reduction is performed with several different suites of basis functions. After numerically solving the reduced order system equations of motion, the physical displacement time history is obtained by an inverse transformation and stresses are recovered. Stress ranges obtained through the rainflow counting procedure are used in a linear damage accumulation method to yield fatigue estimates. Fatigue life estimates obtained using various basis functions in the reduced order method are compared with those obtained from numerical simulation in physical degrees-of-freedom.
\end{abstract}

Keywords: nonlinear random response, thermal loading, high-cycle-fatigue, reduced order methods.

\section{Introduction}

Direct numerical simulation of nonlinear random response in physical degrees-offreedom (DoFs) is computationally intensive for even the simplest structures. Its use for design of high-cycle-fatigue tolerant aerospace vehicle structures is considered impractical. Accordingly, much effort has been spent in recent years to develop accurate reduced order analyses, which could be suitable for use in design environments.

Finite-element-based nonlinear modal numerical simulation methods have been the focus of much of the research effort as they offer the ability to investigate practical structures. Such methods may be viewed as being in one of two categories; those in which the nonlinear modal stiffness is directly evaluated from the nonlinear finite element stiffness matrix (so-called direct methods), and those in which the nonlinear modal stiffness is indirectly evaluated. Direct methods are typically 
In Proceedings of The Seventh International Conference on Computational Structures Technology, Topping, B.H.V. and Mota Soares, C.A., Eds., Civil-Comp Press, Stirling, United Kingdom, 2004.

implemented in special purpose finite element codes in which the nonlinear stiffness is known, see for example references [1-3]. Indirect stiffness evaluation methods are typically implemented for use with commercial finite element codes in which the nonlinear stiffness is unavailable, see for example references [4, 5]. For both direct and indirect stiffness evaluation approaches, the crux of the problem lies in the selection of the proper basis, through which the nonlinear modal stiffness may be determined. Through comparison with numerical simulation in physical DoFs, the authors recently demonstrated [6] the ability of a reduced order method to accurately predict geometrically nonlinear random displacement and stress response, provided that a suitable modal basis is utilized. The focus of this paper is to extend that work to determine the effect of modal basis selection on high-cycle-fatigue life estimation.

The problems of interest are those that exhibit nonlinear bending-membrane coupling. This coupling dramatically changes the stress response characteristics with increasing load, as shown by direct numerical simulation results in Figure 1 Figure 4 for a clamped-clamped beam under distributed loading. For low-level excitation, the total surface stress response has a zero mean component (Figure 1), has a Gaussian probability density function (PDF) distribution and is typically dominated by the bending component (Figure 3). As the excitation level increases, the contribution of membrane stress to the total becomes more significant, resulting in a non-zero mean (Figure 1) which skews the total stress PDF from Gaussian (Figure 2). Additionally for the spring hardening case shown, the stress power spectral density (PSD) exhibits peak broadening and shifting to higher frequencies (Figure 4), and indicates significant peaks due solely to the membrane component. From a mechanics point of view, the reduced order analysis must be capable of accurately predicting all of these behaviors. However, from the fatigue point of view, the stress range PDF and stress ratio govern the fatigue life estimate for a given material system. Thus, for fatigue analysis, the reduced order method should be sufficient if it can accurately predict these quantities.

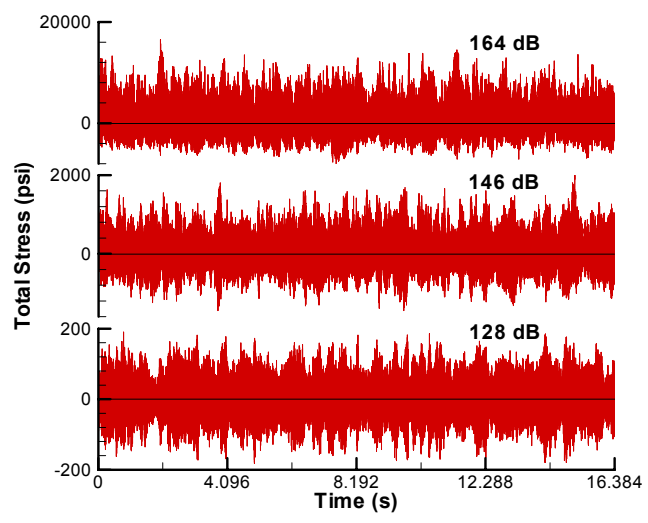

Figure 1: Quarter-span total stress time history at different load levels.

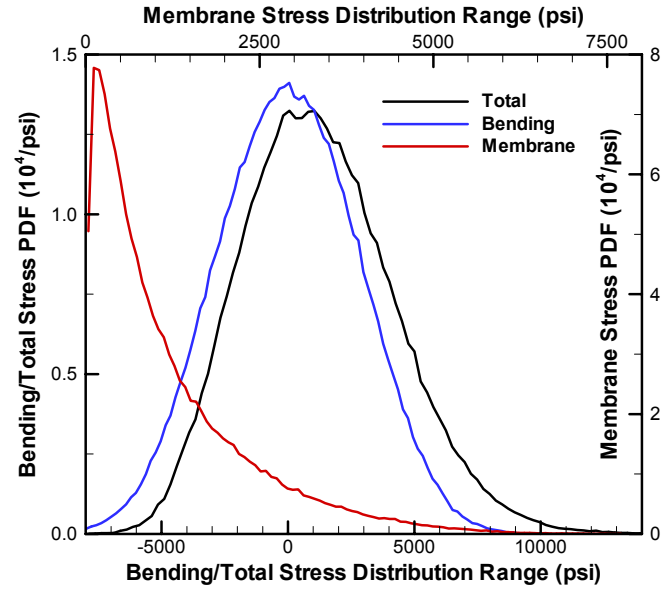

Figure 2: Quarter-span component stress probability density at $164 \mathrm{~dB}$.

In an effort to determine what selection of basis functions most accurately predicts the stress range PDF and stress ratio, several bases are considered including 
In Proceedings of The Seventh International Conference on Computational Structures Technology, Topping, B.H.V. and Mota Soares, C.A., Eds., Civil-Comp Press, Stirling, United Kingdom, 2004.

(i) bending modes only; (ii) coupled bending and companion modes; (iii) three variations of uncoupled bending and companion [7, 8] modes; and (iv) bending and membrane modes. Results are compared with those obtained from numerical simulation in physical DoFs. A planar aluminum beam in a pre-buckled regime is considered to keep the computational cost of the numerical simulation in physical DoFs reasonable. Two locations along the span of the beam are investigated - one at the clamped end where the bending stress component is dominant and one at a location close to the quarter-span, where the effect of membrane stress is more significant.

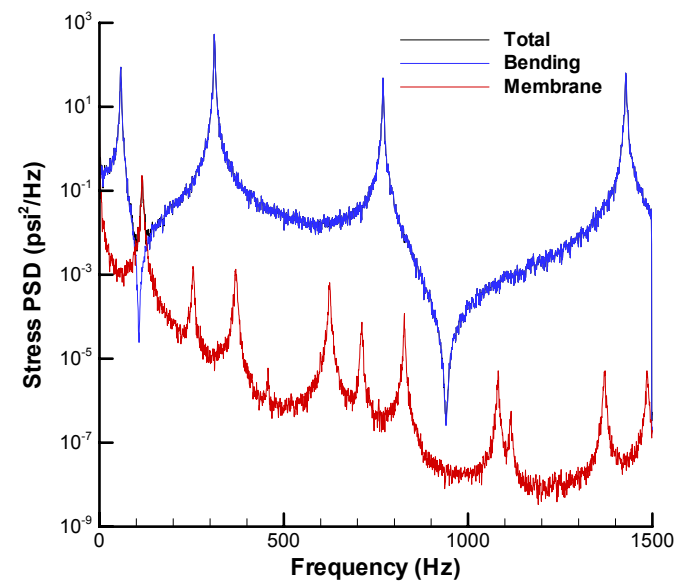

Figure 3: Quarter-span component stress PSD at $128 \mathrm{~dB}$.

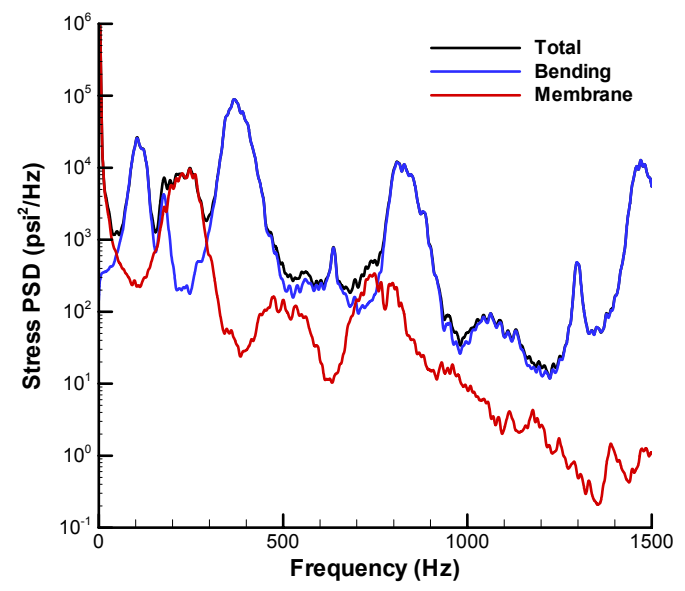

Figure 4: Quarter-span component stress PSD at $164 \mathrm{~dB}$.

\section{Nonlinear Modal Simulation}

The nonlinear modal simulation analysis consists of several parts. The linear system matrices are first obtained from a commercial finite-element program. One or more methods, to be discussed, are next used to obtain a modal basis. Following a transformation of the nonlinear system to modal coordinates, the modal stiffness coefficients are evaluated and the resulting coupled system of equations is numerically integrated to obtain the modal displacement time history. These are transformed back to physical coordinates for post-processing, including stress recovery.

\subsection{Modal Coordinate Transformation}

The equations of motion of the nonlinear system in physical degrees-of-freedom may be written as

$$
\boldsymbol{M} \ddot{\boldsymbol{X}}(t)+\boldsymbol{C} \dot{\boldsymbol{X}}(t)+\boldsymbol{F}_{N L}(\boldsymbol{X}(t))=\boldsymbol{F}(t) .
$$

where $\boldsymbol{M}$ and $\boldsymbol{C}$ are the mass and proportional damping matrices, respectively, $\boldsymbol{X}$ and $\boldsymbol{F}$ are the displacement response and force excitation vectors, respectively. The nonlinear restoring force $\boldsymbol{F}_{N L}$ contains the linear, quadratic and cubic stiffness terms. 
In Proceedings of The Seventh International Conference on Computational Structures Technology, Topping, B.H.V. and Mota Soares, C.A., Eds., Civil-Comp Press, Stirling, United Kingdom, 2004.

A set of coupled modal equations with reduced degrees-of-freedom is first obtained by applying the modal coordinate transformation $X=\Phi q$ to Equation (1), where $\boldsymbol{q}$ is the modal displacement response vector. The modal basis function matrix $\Phi$ is typically formed from the eigenvectors obtained from Equation (1) using only the linear stiffness. For flat isotropic structures, these may include any combination of bending and membrane modes. In lieu of membrane modes, the modal basis may include "companions" related to the membrane response, as discussed in the next section. Generally, a small set of $L$ basis functions are included giving

$$
\tilde{\boldsymbol{M}} \ddot{\boldsymbol{q}}(t)+\tilde{\boldsymbol{C}} \dot{\boldsymbol{q}}(t)+\tilde{\boldsymbol{F}}_{N L}\left(q_{1}(t), q_{2}(t), \ldots, q_{L}(t)\right)=\tilde{\boldsymbol{F}}(t)
$$

where the tilde superscript represents modal quantities, and

$$
\tilde{\boldsymbol{M}}=\boldsymbol{\Phi}^{T} \boldsymbol{M} \boldsymbol{\Phi} \quad \tilde{\boldsymbol{C}}=\boldsymbol{\Phi}^{T} \boldsymbol{C} \boldsymbol{\Phi}=\left\lceil 2 \zeta_{r} \omega_{r}\right\rfloor \quad \tilde{\boldsymbol{F}}_{N L}=\boldsymbol{\Phi}^{T} \boldsymbol{F}_{N L} \quad \tilde{\boldsymbol{F}}=\boldsymbol{\Phi}^{T} \boldsymbol{F} .
$$

\subsection{Modal Basis Calculation}

For the problems of interest in this paper, both bending and membrane behavior should be included in the basis selection since the large deflection nonlinearity couples their response. The basis functions may be determined via several methods. Basis functions corresponding to the bending and membrane response may be determined through solution of the linear eigenvalue problem. Other basis functions corresponding to the membrane response induced by bending-membrane coupling may be determined via alternative approaches.

\subsubsection{Linear eigenvectors}

In this study, only isotropic materials or laminated composite materials having zero laminate coupling stiffness $([\mathrm{B}]=0)$ are considered. Further, the current work is restricted to planar structures. The linear eigenvectors obtained from Equation (1) (using only the linear stiffness) are therefore uncoupled and are either associated with low-frequency bending modes or high-frequency membrane modes. The selection of which bending modes to include depends on both the excitation bandwidth and the loading distribution. The identification of each selected bending mode is straightforward as they are typically the lowest frequency modes. The selection of which membrane modes to include is less apparent. All or most membrane modes will likely fall outside the excitation bandwidth. Furthermore, the identification of any particular membrane mode may be difficult and time consuming. Nevertheless, a reasonable starting point is to select the lowest membrane modes that are consistent with the loading distribution. Inclusion of both these eigenvectors in the modal basis is subsequently referred to as the bending and membrane mode (BM) case. Inclusion of only the bending eigenvectors will be referred to as the bending mode only (B) case.

In this study, the mass-normalized linear eigenvectors without the effect of thermal stress were obtained using MSC.NASTRAN normal modes analysis 
In Proceedings of The Seventh International Conference on Computational Structures Technology, Topping, B.H.V. and Mota Soares, C.A., Eds., Civil-Comp Press, Stirling, United Kingdom, 2004.

(solution 103). These are the so-called "cold" modes. The mass-normalized linear eigenvectors with the effect of thermal stress, i.e. "hot" modes, requires MSC.NASTRAN nonlinear static analysis (solution 106).

\subsubsection{Companion Basis Functions}

An alternative approach to using membrane modes is the use of so-called companion [7] (or dual [8]) modes. These modes represent the membrane behavior resulting from bending due to bending-membrane coupling. Previous authors utilized quasi-static approaches to determine the companion mode via nonlinear static analyses.

A new method was recently presented for computing the companion mode using a dynamic analysis [6]. An initial stress-free imperfection in the shape of the first bending mode is introduced in the flat structure to couple the bending-membrane response. The magnitude of the imperfection is chosen to be very small such that a normal modes analysis yields virtually the same bending eigenvalues and eigenvectors as that of the flat structure. For the cold modes, MSC.NASTRAN solution 103 was again used to compute the mass-normalized eigenvectors, which now contain both the bending and membrane behaviors, but at the natural frequencies of the original flat structure. Direct inclusion of these eigenvectors in the modal basis is subsequently referred to as the coupled bending and companion mode $(\mathrm{CBC})$ case. A more consistent usage relative to the $\mathrm{BM}$ basis, however, is to separate the degrees-of-freedom (DoFs) associated with the bending and membrane behaviors. In practice, since the bending behavior is unchanged, the original mass normalized low-frequency bending modes are retained. The bending DoFs are set to zero in the newly obtained eigenvector to obtain the dynamic companion. Inclusion of both these eigenvectors in the modal basis, independently or in pairs, is subsequently referred to as the uncoupled bending and companion mode (UBC) case. It should be noted that although the $\mathrm{CBC}$ basis functions are mass normalized, companions in the UBC set are not mass normalized. This is because they are obtained through separation of bending and membrane related components from the mass-normalized CBC. Previous work by the authors [6] utilized the non-massnormalized UBC companions. This paper additionally considers the use of massnormalized UBC companions.

\subsection{Indirect Stiffness Evaluation Method}

The indirect stiffness evaluation method previously developed without the effect of thermal loading [5] was further developed for thermal loadings [8]. To summarize, the nonlinear force vector in Equation (2) may be written in the form

$$
\tilde{F}_{N L}\left(q_{1}, q_{2}, \ldots, q_{L}\right)=\sum_{j=1}^{L} d_{j}^{r} q_{j}+\sum_{j=1}^{L} \sum_{k=j}^{L} a_{j k}^{r} q_{j} q_{k}+\sum_{j=1}^{L} \sum_{k=j}^{L} \sum_{l=k}^{L} b_{j k l}^{r} q_{j} q_{k} q_{l} \quad r=1,2, \ldots, L
$$

where $d, a$, and $b$ are the linear, quadratic nonlinear, and cubic nonlinear modal stiffness coefficients, respectively. This form reduces the problem of determining 
In Proceedings of The Seventh International Conference on Computational Structures Technology, Topping, B.H.V. and Mota Soares, C.A., Eds., Civil-Comp Press, Stirling, United Kingdom, 2004.

the nonlinear stiffness from one in which a large set of simultaneous nonlinear equations must be solved to one involving simple algebraic relations. The algebraic relations are obtained by solving a series of nonlinear static problems with prescribed displacement fields $[5,9]$.

\subsection{Numerical Integration and Element Stress Recovery}

Having the nonlinear force vector in Equation (4) fully defined, the coupled modal nonlinear equations of motion in Equation (2) are numerically integrated using a fourth-order Runge-Kutta method [10]. The resulting modal displacement time histories are transformed back to physical coordinates using the inverse modal transformation.

In contrast to mapping techniques relating stress to physical DoFs $[7,8]$, the approach taken here recovers the element stresses by post-processing the nodal physical DoFs directly within the finite element program. Since the stress postprocessor of the finite element program is used, the stresses are identical to those that would have been obtained via a standard finite element analysis in physical DoFs. The appeal of direct stress recovery over mapping techniques is that it eliminates any issues concerning the accuracy of the mapping, and eliminates the need for estimating nonlinear mapping functions for each stress quantity of interest. The disadvantage is that it can be computationally costly.

In principle, the approach taken is simple. For a single element stress recovery, a finite element mesh is made consisting of two elements. The stress recovery element is of the same type and has the same properties as the element of interest. For a particular output time step, the element physical DoFs, obtained via the nonlinear modal simulation method, are applied to each element node as prescribed displacement fields in the MSC.NASTRAN nonlinear static solution. A nuance of MSC.NASTRAN requires the attachment of a dummy element and load [9] to the stress recovery element, in order to calculate the resulting element nodal forces and recover the element stress. By repeating this operation for each output time step, the stress time history is determined. If stress recovery is required for a region or the entire structure, that portion of the original model is used and a dummy element is attached. The prescribed displacement field spans the entire region of interest.

\section{Fatigue Life Calculation}

A comprehensive study of stress range counting methods for fatigue life prediction [11] concluded that the rainflow counting method provides accurate life estimates. This approach is adopted herein. Using this approach, the stress range PDF is obtained from the stress time history. The fatigue life is estimated using the stress range PDF, appropriate material stress-life $(S-N)$ data, and a linear cumulative damage principle. 
In Proceedings of The Seventh International Conference on Computational Structures Technology, Topping, B.H.V. and Mota Soares, C.A., Eds., Civil-Comp Press, Stirling, United Kingdom, 2004.

\subsection{Rainflow Counting}

The original rainflow counting formulation [12] is cumbersome to implement. The present work utilizes a later formulation [13], which is provided as part of the Wave Analysis for Fatigue and Oceanography (WAFO) Matlab toolbox for analysis of random waves and loads [14].

At each loading level, ten total stress history records were joined together to form an overall record length of $T=16.384 \mathrm{~s}$ for the rainflow cycle counting analysis. The WAFO toolbox was used to compute the turning points for each stress time history, the rainflow cycles from the sequence of turning points, and the stress ranges from the rainflow cycle count. The input stress time history data were not filtered. A histogram was computed from the stress ranges from which the stress range PDF was found by

$$
P\left(S_{i}\right)=\frac{n_{i}}{S_{t} \Delta S}
$$

where $n_{i}$ are the histogram counts and $S_{t}$ is the total number of rainflow cycles. The number of peaks per second, $E[P]$, was determined as

$$
E[P]=\frac{S_{t}}{T}=\frac{S_{t}}{16.384 s} .
$$

\subsection{S-N Data and Stress Ratios}

Under constant amplitude loading, the $S-N$ curve relates the cycles to failure $N$ to the applied stress range $S$ via the relationship:

$$
N S^{m}=K
$$

where $m$ and $K$ are material specific properties. Typically, $S-N$ curves are given for a range of stress ratios

$$
R=S_{\min } / S_{\max }
$$

where $R$ is the stress ratio, and $S_{\min }$ and $S_{\max }$ are the minimum and maximum stress, respectively. For fully reversed loading, $R=-1$. Since this study deals with random stress histories, a statistical measure of the stress ratio is required. A simplified approach was adopted to define the minimum and maximum stress in terms its statistical moments as

$$
S_{\min }=\mu-\sigma / 2 \quad S_{\max }=\mu+\sigma / 2
$$

where $\mu$ and $\sigma$ are stress mean and standard deviation, respectively. 
In Proceedings of The Seventh International Conference on Computational Structures Technology, Topping, B.H.V. and Mota Soares, C.A., Eds., Civil-Comp Press, Stirling, United Kingdom, 2004.

\subsection{Linear Damage Accumulation}

For variable amplitude loading, the Palmgren-Miner linear cumulative damage rule [15] is typically used and assumes that the damage, $D$, caused by stress cycles in one stress range can be calculated and added to damage caused by stress cycles in another stress range, or

$$
D=\sum_{i} \frac{n_{i}}{N\left(S_{i}\right)}
$$

where $n_{i}$ is the number of cycles at stress range $S_{i}$, and $N\left(S_{i}\right)$ are the cycles to failure at stress range $S_{i}$. For random response, it is convenient to recast Equation (10) in the alternative form

$$
D=\frac{E[P] T}{K} \sum_{i} S_{i}^{m} P\left(S_{i}\right) \Delta S
$$

where $P\left(S_{i}\right)$ is the stress range $\mathrm{PDF}, \Delta S$ is the PDF bin width, $E[P]$ is the number of peaks per second, and $T$ is the lifetime. Failure is assumed to occur when the damage sums to 1, giving the fatigue life in seconds from Equation (11) as

$$
\text { Fatigue Life }(\mathrm{s})=\frac{K}{E[P] \sum_{i} S_{i}^{m} P\left(S_{i}\right) \Delta S}
$$

\section{Results}

Studies were conducted on a clamped-clamped aluminium beam measuring 18 -in. $\times 1$-in. $\times 0.09$-in $(0.457 \mathrm{~m} \times 0.025 \mathrm{~m} \times 0.0023 \mathrm{~m})$ subjected to a uniformly distributed transverse loading with a bandwidth of $1500 \mathrm{~Hz}$. Two thermal conditions were investigated; a room temperature condition and an elevated temperature $\Delta \mathrm{T}=5^{\circ} \mathrm{F}\left(9^{\circ} \mathrm{C}\right)$ below the critical thermal buckling temperature $\Delta \mathrm{T}_{\mathrm{CR}}=6.64^{\circ} \mathrm{F}\left(11.95^{\circ} \mathrm{C}\right)$. The following material properties were used:

$$
\begin{aligned}
& E=10.6 \times 10^{6} \mathrm{psi}(73.1 \mathrm{GPa}) \quad G=4.0 \times 10^{6} \mathrm{psi}(27.6 \mathrm{GPa}) \\
& \rho=2.588 \times 10^{-4} \frac{\mathrm{lb} f_{f} s^{2}}{i n^{4}}\left(2768 \frac{\mathrm{kg}}{\mathrm{m}^{3}}\right) \quad \alpha=1.24 \times 10^{-5} \frac{\mathrm{in} / \mathrm{in}}{{ }^{\circ} \mathrm{F}}\left(2.23 \times 10^{-5} \frac{\mathrm{m} / \mathrm{m}}{{ }^{\circ} \mathrm{C}}\right)
\end{aligned}
$$

The MSC.NASTRAN model used for the reduced order numerical simulations consisted of 144 CBEAM elements. Simulations were run for bases B, BM, CBC and UBC mass-normalized. Simulations for the fifth basis, UBC non massnormalized, were run for a subset of conditions. The B basis consisted of the first four symmetric bending modes. For the BM basis, the first four anti-symmetric 
In Proceedings of The Seventh International Conference on Computational Structures Technology, Topping, B.H.V. and Mota Soares, C.A., Eds., Civil-Comp Press, Stirling, United Kingdom, 2004.

membrane modes were added. The CBC and UBC bases consisted of the first four symmetric bending and dynamic companion modes. Damping was chosen to be sufficiently high so that a good comparison could be made at the peaks of the PSD. A level of mass proportional damping was specified corresponding to critical damping of $2.0 \%$ for the first symmetric bending mode.

Numerical simulation analysis in physical coordinates served as the basis for comparison of results from nonlinear modal simulation analyses. The finite element program ABAQUS was to generate nonlinear displacement and stress time histories. The double precision explicit integration scheme with an adaptive time integration step was utilized for all analyses. The mass proportional damping factor used was the same as that specified in the nonlinear modal simulation analyses. The ABAQUS model consisted of 144 B21 elements.

The applied loading had a Gaussian distribution and 10 ensembles of response time histories, each $2.1384 \mathrm{~s}$ in duration, were simulated. The first $0.5 \mathrm{~s}$ were removed from each ensemble to eliminate the transient response. Further details regarding load generation and ensemble averaging are discussed in reference [16].

Displacement results are presented at the $25 \%$ span, or 4.5 -in. $(0.114 \mathrm{~m})$ from the clamped end. Element stresses and fatigue life estimates are presented at 0.0625 -in. $(1.59 \mathrm{~mm})$ from the clamped end (subsequently referred to as 'clamped end') and at 4.4375 -in. $(0.113 \mathrm{~m})$ from the clamped end (subsequently referred to as 'quarterspan'). Such a choice help to elucidate the benefits and liabilities of the various modal bases under severe conditions as the ratio between membrane stress component and bending stress component is expected to vary significantly between the selected locations.

\subsection{Room Temperature}

\subsubsection{Displacement Response}

The transverse displacement PSDs are shown in Figure 5 for the lowest loading of $128 \mathrm{~dB}$ overall sound pressure level (OASPL). For this level, all modal bases give essentially the same results as the numerical simulation in physical DoFs. The membrane displacement PSDs for this load level, shown in Figure 6, offer a different perspective. The BM basis is the only one to compare well with the results from numerical simulation in physical DoFs. The CBC basis is inaccurate on two accounts; the magnitude is clearly incorrect and the shape of the frequency response mimics that of the bending response in Figure 5. Three forms of UBC basis were examined to determine which to carry forward to the fatigue analysis. The nonmass-normalized UBC dynamic basis exhibits a similar character as the physical DoFs results, but at a substantially reduced level. Consequently, this basis is not considered further. The mass-normalized UBC dynamic basis and mass-normalized UBC static basis, obtained using Mignolet's approach [8], bound the physical DoFs results across the frequency range. Consistent with reference [17], it was found that the integration time step had to be substantially reduced in order to keep a stable solution for the mass-normalized UBC static basis. A static condensation in modal coordinates was proposed and demonstrated to mitigate this behavior [17], although 
In Proceedings of The Seventh International Conference on Computational Structures Technology, Topping, B.H.V. and Mota Soares, C.A., Eds., Civil-Comp Press, Stirling, United Kingdom, 2004.

no attempt was made to implement this scheme in the present work. A similar problem was observed for the UBC dynamic basis, though not as severe. Consequently, since the UBC static basis was more sensitive to integration time step and did not predict the membrane displacement behavior any more accurately than the UBC dynamic basis, it was not considered further. Subsequent reference to UBC shall indicate the mass-normalized UBC dynamic basis. It should be noted that the BM basis, containing high frequency membrane modes, did not experience numerical integration problems. Therefore, contrary to [17], the numerical integration problem with the mass-normalized UBC bases does not appear to be exclusively associated with the presence of high frequency modes.

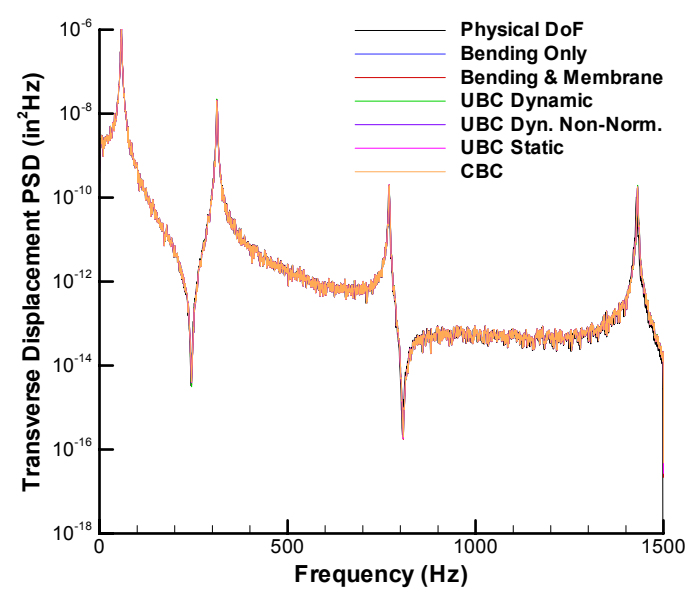

Figure 5: Quarter-span transverse displacement PSD at $128 \mathrm{~dB}$.

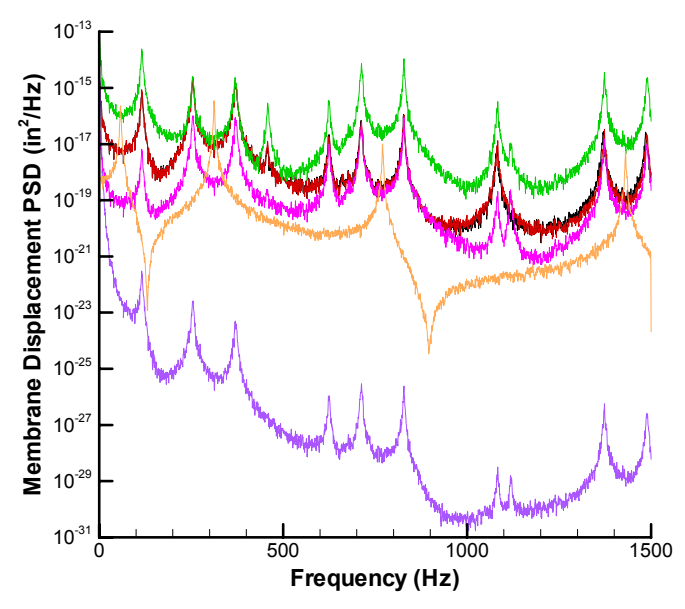

Figure 6: Quarter-span membrane displacement PSD at $128 \mathrm{~dB}$.

\subsubsection{Stress Response}

The total stress PSDs at the clamped end for the excitations levels of 146, 152, and $164 \mathrm{~dB}$ OASPL are shown in Figure 7 - Figure 9, respectively. It is seen that the stress response at this location is dominated by the fundamental mode. As the excitation level increases, the peaks broaden and shift towards higher frequencies. The BM results compare most favourably with the solution in physical DoFs for all excitations levels studied. For the excitation levels of 146 and $152 \mathrm{~dB}$, the responses provided by $\mathrm{B}$ and $\mathrm{CBC}$ bases are virtually the same, and differ insignificantly from each other at $164 \mathrm{~dB}$. Bases $\mathrm{B}$ and $\mathrm{CBC}$ however exhibit some undesirable characteristics - they do not provide membrane contribution from the fundamental mode (no membrane peak at $120-150 \mathrm{~Hz}$ for the two lower loadings considered) and tend to under-predict the magnitudes of bending related peaks and over-predict their broadening. The UBC solution was available only for the two lower loadings considered. The use of UBC bases improves the response characteristics for the first two lowest bending modes compared with the $\mathrm{B}$ and $\mathrm{CBC}$ bases, and also captures the membrane related behaviour resulting from the fundamental mode. Above 500 $\mathrm{Hz}$, the comparison between physical DoFs and UBC is the least favourable. 
In Proceedings of The Seventh International Conference on Computational Structures Technology, Topping, B.H.V. and Mota Soares, C.A., Eds., Civil-Comp Press, Stirling, United Kingdom, 2004.

The quarter-span total stress PSDs for excitations of 146 and $164 \mathrm{~dB}$ are shown in Figure 10 and Figure 11, respectively. The stress response at this location is clearly dominated by the second mode. Again the BM bases compare most favourably with the physical DoFs solution. Bases $\mathrm{B}$ and $\mathrm{CBC}$ again result in the virtually same response at the lower excitation level, and show only minor differences at the higher excitation level. Both under-predict the bending peak magnitudes and over-predict the first membrane peak magnitude. At $146 \mathrm{~dB}$, the UBC basis under-predicts the first bending and the first period-doubled peak magnitudes and over-predicts the magnitude of second bending peak. All bases apart from BM result in an excessive third and forth peak broadening.

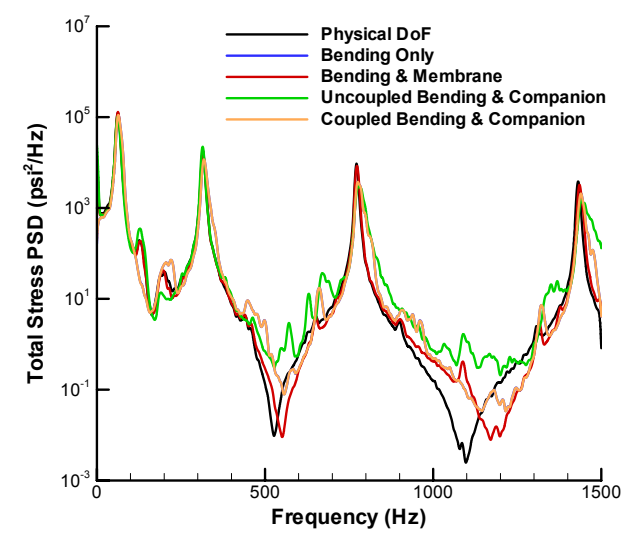

Figure 7: Total stress PSD at clamped end for $146 \mathrm{~dB}$ loading.

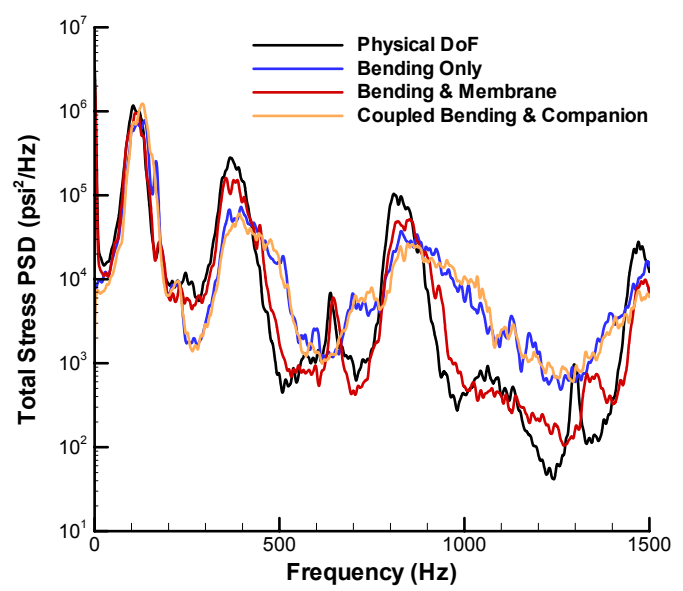

Figure 9: Total stress PSD at clamped end for $164 \mathrm{~dB}$ loading.

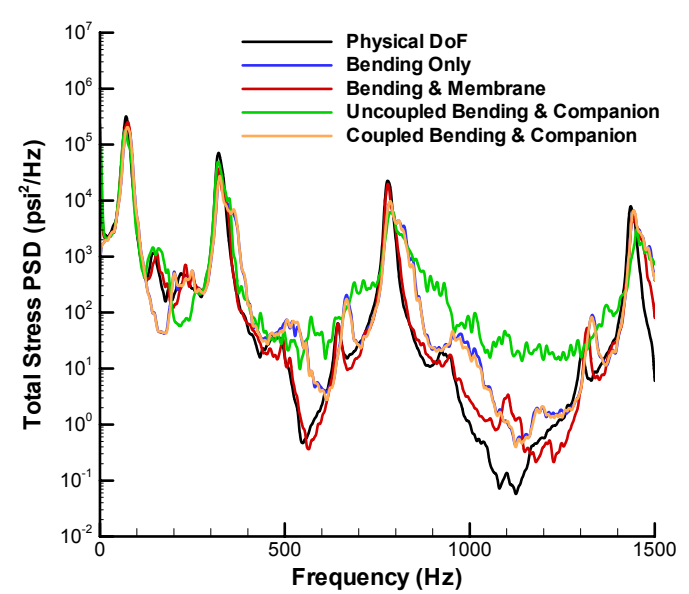

Figure 8: Total stress PSD at clamped end for $152 \mathrm{~dB}$ loading.

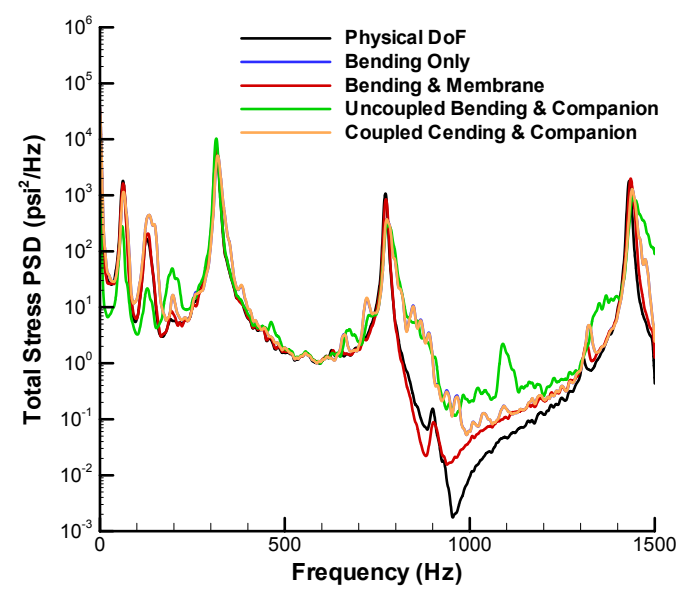

Figure 10: Total stress PSD at quarterspan for $146 \mathrm{~dB}$ loading. 
In Proceedings of The Seventh International Conference on Computational Structures Technology, Topping, B.H.V. and Mota Soares, C.A., Eds., Civil-Comp Press, Stirling, United Kingdom, 2004.

\subsubsection{Fatigue Analysis}

The stress range PDFs for the clamped end for loadings of 146 and $164 \mathrm{~dB}$ are shown in Figure 12 and Figure 13, respectively. For the $146 \mathrm{~dB}$ level, stress range PDFs from all bases compare well with those from the physical DoFs simulation, up to approximately $6.5 \mathrm{ksi}(44.8 \mathrm{MPa})$, above which the UBC basis is significantly lower than the rest. The highest value of stress range PDF is maintained by physical DoFs solution, followed by the B basis solution. At the $164 \mathrm{~dB}$ level, the stress range PDF comparison is good only until approximately half of the maximum stress range, see Figure 13. Above a stress range of $45 \mathrm{ksi}(310 \mathrm{MPa})$, the analysis in physical DoFs yields significantly higher stress ranges than any of the reduced order analyses. The highest stress range PDF values are most important in the fatigue estimate as these induce the most damage.

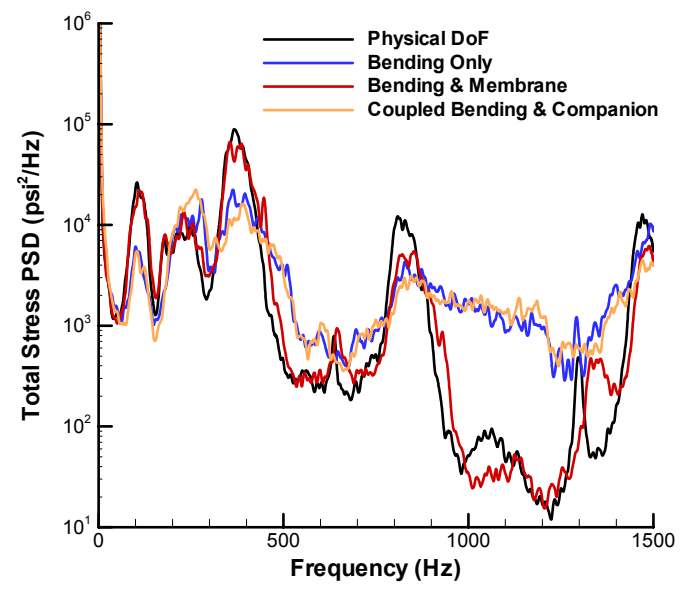

Figure 11: Total stress PSD at quarterspan for $164 \mathrm{~dB}$ loading.

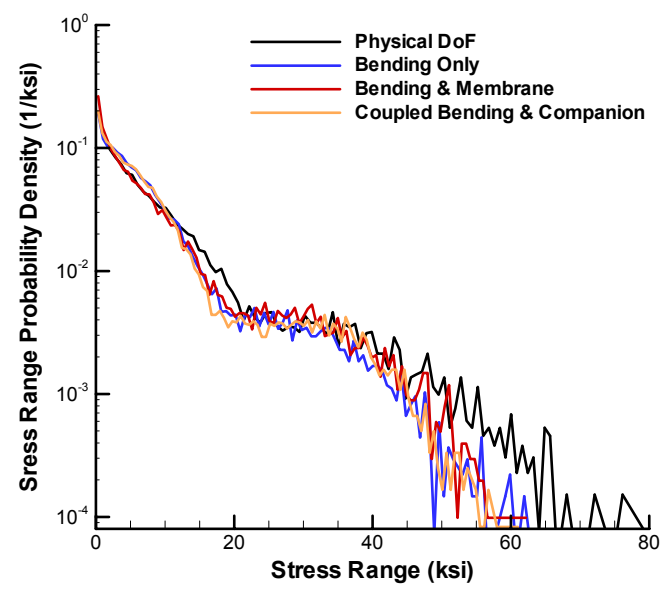

Figure 13: Stress range PDF at clamped end for $164 \mathrm{~dB}$ loading.

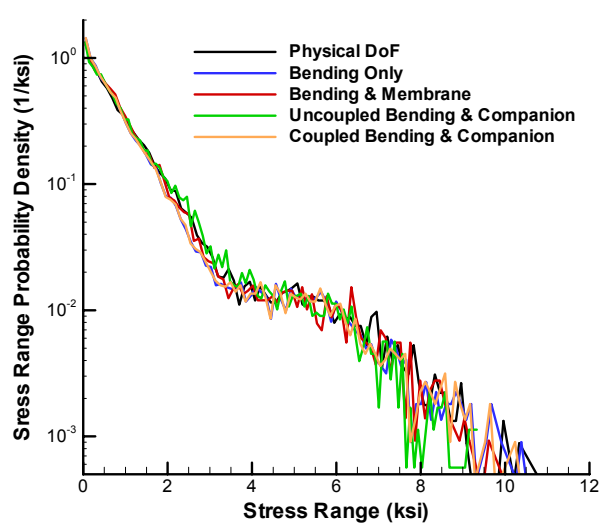

Figure 12: Stress range PDF at clamped end for $146 \mathrm{~dB}$ loading.

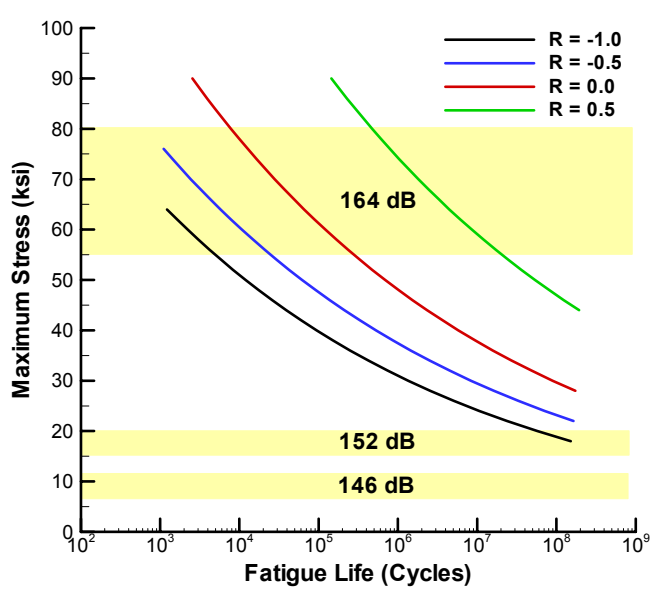

Figure 14: $S-N$ curves for different stress ratios [18]. 
In Proceedings of The Seventh International Conference on Computational Structures Technology, Topping, B.H.V. and Mota Soares, C.A., Eds., Civil-Comp Press, Stirling, United Kingdom, 2004.

In the following fatigue life analyses, $S-N$ properties for 7075 -T6 aluminum were used in Equation (12), as shown in Figure 14 for a range of stress ratios. In this figure, the band of maximum stress ranges corresponding to the clamped end are highlighted for the excitation levels considered. Assuming a fully reversed stress response $(R=-1)$, the corresponding fatigue life estimates are shown in Table 1 . Consistent with the observations made of Figure 12 and Figure 13, all reduced order analyses yielded non-conservative estimates, with the UBC basis exhibiting the largest difference. Note that maximum stress ranges at the 146 and $152 \mathrm{~dB}$ levels fall at or below the fatigue life run-out. In this region, small differences in stress range cause large changes in fatigue life estimate. For this reason, fatigue life estimates for all but the UBC basis are considered quite good at the 146 and $152 \mathrm{~dB}$ levels, even if they are non-conservative. For the $164 \mathrm{~dB}$ loading, note that while the maximum stress range exceeded the material yield stress of $72 \mathrm{ksi}(496 \mathrm{MPa})$, the maximum stress itself was less than $50 \mathrm{ksi}(345 \mathrm{MPa})$. Therefore, material nonlinearity was not introduced.

\begin{tabular}{|c|c|c|c|c|c|c|c|}
\hline Location & $\begin{array}{c}\text { OASPL } \\
(\mathrm{dB})\end{array}$ & Units & $\begin{array}{c}\text { Physical } \\
\text { DoF }\end{array}$ & $\mathrm{B}$ & $\mathrm{BM}$ & $\mathrm{CBC}$ & $\mathrm{UBC}$ \\
\hline \multirow{2}{*}{$\begin{array}{c}\text { Clamped } \\
\text { End }\end{array}$} & 146 & Years & 408.7 & 432.7 & 648.1 & 448.1 & 1341.2 \\
\cline { 2 - 8 } & 152 & Years & 0.817 & 1.990 & 1.638 & 2.259 & 5.193 \\
\cline { 2 - 8 } & 164 & Minutes & 2.436 & 11.88 & 16.61 & 20.05 & $\mathrm{n} / \mathrm{a}$ \\
\hline \multirow{2}{*}{$\begin{array}{c}\text { Quarter- } \\
\text { Span }\end{array}$} & 146 & Years $\left(\mathrm{x} 10^{7}\right)$ & 2.025 & 2.087 & 1.907 & 2.087 & 0.967 \\
\cline { 2 - 8 } & 152 & Years $\left(\mathrm{x} 10^{5}\right)$ & 2.781 & 5.236 & 2.207 & 6.710 & 0.04345 \\
\cline { 2 - 8 } & 164 & Days & 112.87 & 47.189 & 91.438 & 165.84 & $\mathrm{n} / \mathrm{a}$ \\
\hline
\end{tabular}

Table 1: Fatigue life estimates for room temperature condition $(R=-1)$.

Although the fatigue life of this beam structure will be dictated by the damage accumulated at the clamped end, it is of interest to investigate the quality of fatigue life estimates at the quarter-span location, where the effect of membrane stress is more significant. Stress range PDFs for the quarter-span location are shown in Figure 15 and Figure 16, and fatigue life estimates are given in Table 1. Although the fatigue estimates for this location at 146 and $152 \mathrm{~dB}$ are in the fatigue life runout regime and outside the bounds of practical interest, valuable conclusion can be drawn by contrasting these results with the clamped end estimates. For $146 \mathrm{~dB}$ excitation level shown in Figure 15, stress ranges compare very well through the maximum range for all the analyses considered except the UBC basis. Results found using the UBC basis indicated considerably higher values of stress range beginning at approximately $2.5 \mathrm{ksi}(17.2 \mathrm{MPa})$, which translates to a very conservative fatigue estimate. Fatigue estimates computed using the B, BM and $\mathrm{CBC}$ bases compared favourably with the physical DoFs estimate. However, unlike the clamped end, fatigue life estimates at the quarter-span were in some cases conservative and in some case non-conservative. At the quarter-span location, the membrane to bending stress ratio is higher than at the clamped end of the beam. It therefore comes as no surprise that the BM basis produces the most accurate fatigue estimates at 152 and $164 \mathrm{~dB}$, where nonlinear effects are the most significant. For the $164 \mathrm{~dB}$ level, Figure 16 shows the $\mathrm{B}$ basis having the highest stress ranges, producing the most conservative fatigue life estimate. 
In Proceedings of The Seventh International Conference on Computational Structures Technology, Topping, B.H.V. and Mota Soares, C.A., Eds., Civil-Comp Press, Stirling, United Kingdom, 2004.

\subsubsection{Effect of Mean Stress}

To gain additional insight into how the differences in the predicted stress response are reflected in the fatigue calculation, the mean $\mu$ and standard deviation $\sigma$ of the total stress are shown in Table 2 and Table 3, respectively. The BM basis is the only one to accurately capture the mean value predicted by simulation in physical DoFs for both clamped and quarter-span locations. The B and $\mathrm{CBC}$ bases both result in zero mean stress for the clamped end and over-predicted mean stress at the quarter-span location. The UBC basis shows the opposing trend of overpredicting the mean value at the clamped end and under-predicting it at the quarterspan. In almost all the cases considered in this study, results computed using the reduced order simulation underestimated the standard deviation obtained from simulation in physical DoFs, as shown in Table 3. Overall, the best comparisons were obtained using the BM basis. As in the case of mean stress, the B and CBC bases again resulted in very similar total stress standard deviations. Inaccuracies in stress mean and standard deviation can affect the fatigue life estimation in two ways. It alters the calculated stress range PDF and consequently the fatigue life. Further, it alters the stress ratio $R$, which dictates the particular $S-N$ data used.

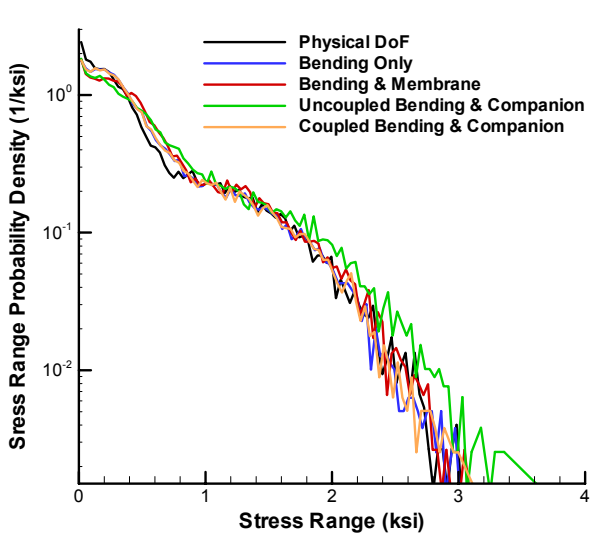

Figure 15: Stress range PDF at quarterspan for $146 \mathrm{~dB}$ loading.

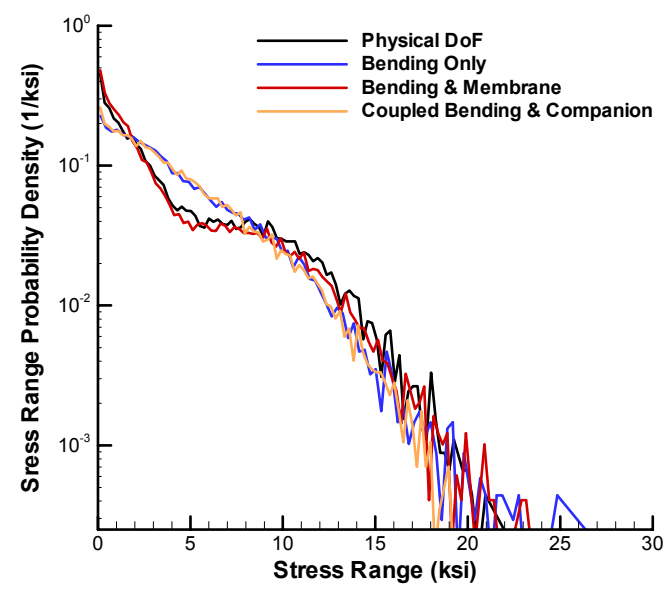

Figure 16: Stress range PDF at quarterspan for $164 \mathrm{~dB}$ loading.

\begin{tabular}{|c|c|c|c|c|c|c|}
\hline Location & $\begin{array}{c}\text { OASPL } \\
(\mathrm{dB})\end{array}$ & $\begin{array}{c}\text { Physical } \\
\text { DoF }\end{array}$ & $\mathrm{B}$ & $\mathrm{BM}$ & $\mathrm{CBC}$ & $\mathrm{UBC}$ \\
\hline \multirow{2}{*}{$\begin{array}{c}\text { Clamped } \\
\text { End }\end{array}$} & 146 & 69.03 & 0.52 & 64.45 & -0.67 & 102.73 \\
\cline { 2 - 7 } & 152 & 210.26 & -1.04 & 190.33 & -4.27 & 319.31 \\
\cline { 2 - 7 } & 164 & 1210.7 & 11.87 & 1039.6 & 15.43 & $\mathrm{n} / \mathrm{a}$ \\
\hline \multirow{2}{*}{$\begin{array}{c}\text { Quarter- } \\
\text { Span }\end{array}$} & 146 & 68.74 & 120.94 & 70.71 & 121.29 & 17.87 \\
\cline { 2 - 7 } & 152 & 214.72 & 295.06 & 213.90 & 285.19 & 62.15 \\
\cline { 2 - 7 } & 164 & 1223.7 & 1473.9 & 1361.4 & 1586.2 & $\mathrm{n} / \mathrm{a}$ \\
\hline
\end{tabular}

Table 2: Total stress mean (psi) for room temperature condition. 
In Proceedings of The Seventh International Conference on Computational Structures Technology, Topping, B.H.V. and Mota Soares, C.A., Eds., Civil-Comp Press, Stirling, United Kingdom, 2004.

With regard to the effect on stress range PDF, it is helpful to investigate the rainflow counting (RFC) matrix. The RFC matrix for the clamped end at the $152 \mathrm{~dB}$ loading is shown in Figure 17 and Figure 18. The BM basis, which correctly predicts the total stress mean, is similarly skewed as the physical DoF solution, as shown in Figure 17. The skewness $(\lambda)$ of the total stress for the BM basis is 0.24 versus 0.3 for the analysis in physical DoFs. Recall from Figure 2 that the membrane component alone accounts for the mean value and hence for the skewness of the total stress response. By contrast, the $\mathrm{B}$ and $\mathrm{CBC}$ bases, which have near zero mean stress, are not skewed and form min-max stress counts along the dashed line of Figure 17 and Figure 18. The UBC basis overestimates the mean total stress and results in excessive skewness (0.37). Finally, the maximum stress indicated by the solution in physical DoFs exceeds all of the reduced order analyses, in agreement with the standard deviation of Table 3.

\begin{tabular}{|c|c|c|c|c|c|c|}
\hline Location & $\begin{array}{c}\text { OASPL } \\
(\mathrm{dB})\end{array}$ & $\begin{array}{c}\text { Physical } \\
\text { DoF }\end{array}$ & $\mathrm{B}$ & $\mathrm{BM}$ & $\mathrm{CBC}$ & $\mathrm{UBC}$ \\
\hline \multirow{2}{*}{$\begin{array}{c}\text { Clamped } \\
\text { End }\end{array}$} & 146 & 1378.8 & 1363.7 & 1348.9 & 1360.3 & 1299.6 \\
\cline { 2 - 7 } & 152 & 2685.0 & 2414.3 & 2518.9 & 2351.9 & 2344.2 \\
\cline { 2 - 7 } & 164 & 8751.3 & 7601.3 & 7920.3 & 7854.7 & $\mathrm{n} / \mathrm{a}$ \\
\hline \multirow{2}{*}{$\begin{array}{c}\text { Quarter- } \\
\text { Span }\end{array}$} & 146 & 407.23 & 407.20 & 408.30 & 406.89 & 421.22 \\
\cline { 2 - 7 } & 152 & 867.72 & 794.76 & 822.15 & 767.97 & 870.67 \\
\cline { 2 - 7 } & 164 & 2985.9 & 2663.6 & 2951.2 & 2621.8 & $\mathrm{n} / \mathrm{a}$ \\
\hline
\end{tabular}

Table 3: Total stress standard deviation (psi) for room temperature condition.

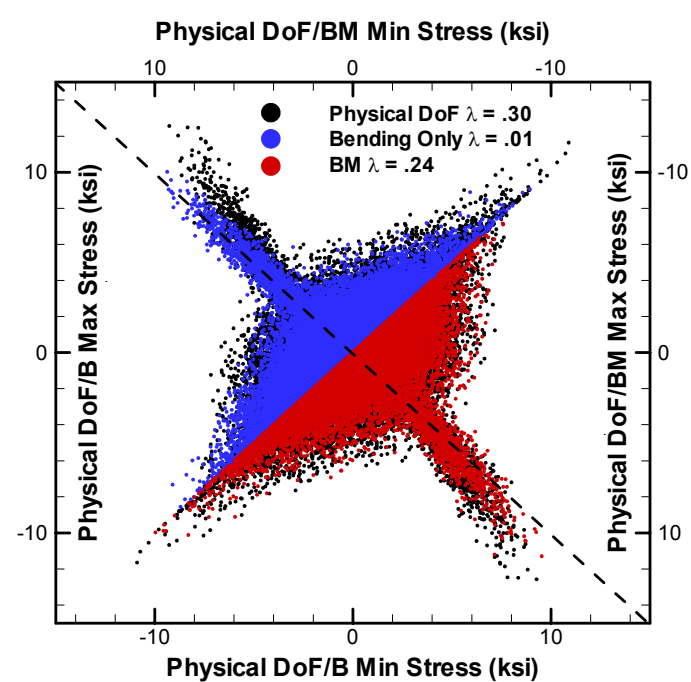

Figure 17: Total stress RFC matrix at clamped end for $152 \mathrm{~dB}$ loading for $\mathrm{B}$ and BM bases.

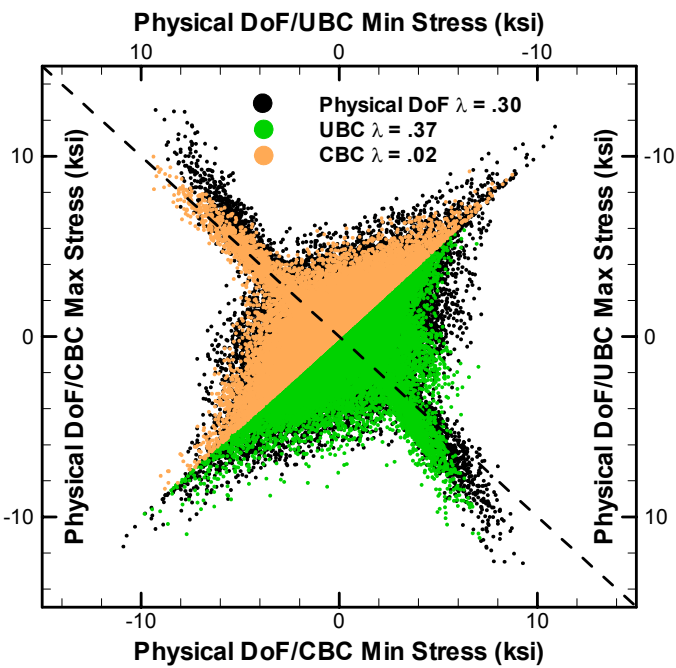

Figure 18: Total stress RFC matrix at clamped end for $152 \mathrm{~dB}$ loading for companion bases.

From the data presented in Table 2, it was seen that the mean stress increases with increasing nonlinear response. This alters the stress ratio as per Equations (8) 
In Proceedings of The Seventh International Conference on Computational Structures Technology, Topping, B.H.V. and Mota Soares, C.A., Eds., Civil-Comp Press, Stirling, United Kingdom, 2004.

and (9), dictating the use of a different S-N curve from the data in Figure 14. To demonstrate the effect of stress ratio, the fatigue life at the clamped end for the 152 $\mathrm{dB}$ loading was re-evaluated. Stress ratios were calculated using the total stress mean and standard deviations in Table 2 and Table 3. For the physical DoF solution and $\mathrm{BM}$ and $\mathrm{UBC}$ bases, the computed stress ratio and corresponding fatigue life estimates are shown in Table 4. The effect of using the actual stress ratio shifts the $S-N$ curve to the right and results in a higher fatigue life estimate. Since the B and $\mathrm{CBC}$ bases produced nearly zero total stress mean values, the stress ratio calculated through this procedure would inaccurately indicate a fully reversed value of $R=-1$. Figure 19 and Figure 20 show the reason why the total stress mean obtained using the $\mathrm{B}$ and $\mathrm{CBC}$ bases for this case is deficient. The bending stress in Figure 19 indicates the same mean value for all analyses. However, relative to the physical DoF analysis results, the $\mathrm{B}$ and $\mathrm{CBC}$ bases grossly underestimate the membrane stress component throughout the entire frequency range, as seen in Figure 20. The most significant effect on the membrane mean stress comes from its zero frequency mean component, which is reduced by more than 2 orders of magnitude from the physical DoF analysis mean.

\begin{tabular}{|c|c|c|c|c|c|}
\cline { 2 - 6 } \multicolumn{1}{c|}{} & $\begin{array}{c}\text { Physical } \\
\text { DoF }\end{array}$ & $\mathrm{B}$ & $\mathrm{BM}$ & $\mathrm{CBC}$ & $\mathrm{UBC}$ \\
\hline Fatigue Life & $3.526 /$ & $9.093 /$ & $7.299 /$ & $10.311 /$ & $21.510 /$ \\
(years) / & -0.73 & $-0.72^{*}$ & -0.74 & $-0.71^{*}$ & -0.57 \\
\cline { 2 - 6 } & $0.817 /$ & $1.990 /$ & $1.638 /$ & $2.259 /$ & $5.193 /$ \\
Stress Ratio $(R)$ & -1.00 & -1.00 & -1.00 & -1.00 & -1.00 \\
\hline
\end{tabular}

Table 4: Clamped end fatigue life estimates at $152 \mathrm{~dB}$ using calculated stress ratios. Asterisk indicates mean stress static correction applied.

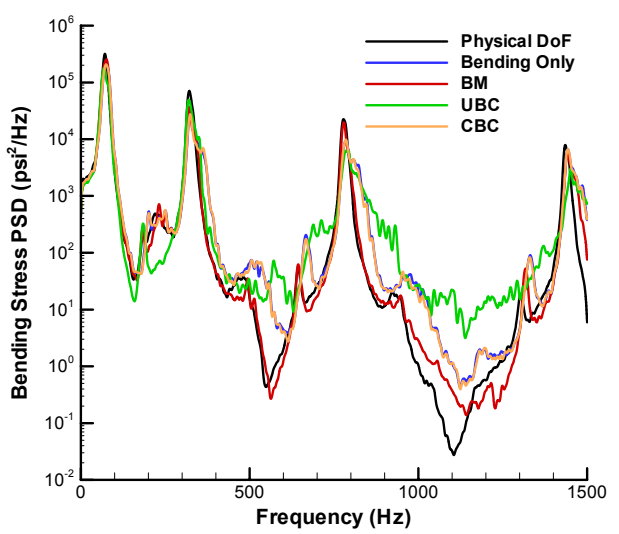

Figure 19: Clamped end bending stress for $152 \mathrm{~dB}$ loading.

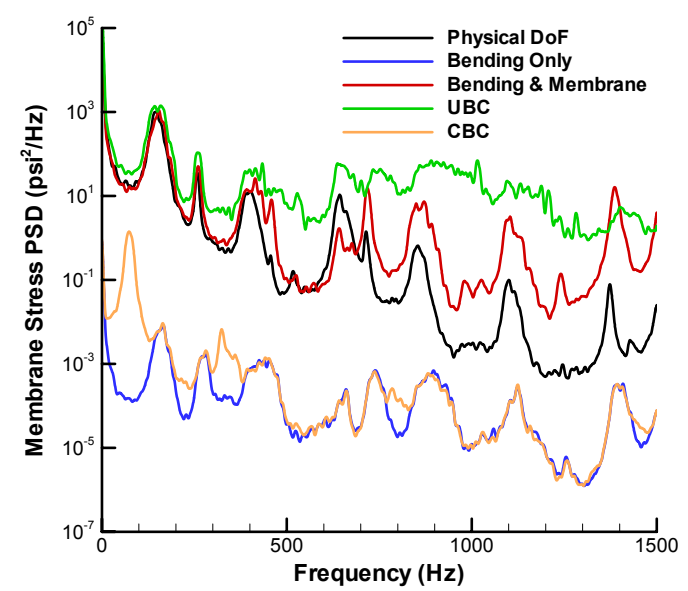

Figure 20: Clamped end membrane stress for $152 \mathrm{~dB}$ loading.

An alternative approach to computing the stress ratio for B and $\mathrm{CBC}$ analysis was undertaken following the approach proposed in reference [19]. For a range of applied random loading, the RMS transverse deflection at the mid-span of the beam 
In Proceedings of The Seventh International Conference on Computational Structures Technology, Topping, B.H.V. and Mota Soares, C.A., Eds., Civil-Comp Press, Stirling, United Kingdom, 2004.

was found. A static analysis was then performed with the same load distribution such that it produced the same static deflection at the mid-span as the RMS deflection. For the particular location of interest, the ratio between static membrane and bending stress was found. Using the assumption that the ratio of RMS membrane to bending stress was the same as static membrane to bending stress, the RMS membrane stress can be estimated from

$$
\left(S_{\text {membrane }}\right)_{\text {RMS }} \approx\left(S_{\text {bending }}\right)_{\text {RMS }}\left(S_{\text {membrane }} / S_{\text {bending }}\right)_{\text {Static }}
$$

where $\left(\mathrm{S}_{\text {bending }}\right)_{\mathrm{RMS}}$ is obtained from the time history of the bending stress. Further assuming that the membrane response is dominated by a single mode, the membrane mean can be written as

$$
\left(S_{\text {membrane }}\right)_{\text {Mean }}=1 / 2\left(S_{\text {membrane }}\right)_{\text {Peak }}=\sqrt{2} / 2\left(S_{\text {membrane }}\right)_{\text {RMS }} .
$$

Finally, since the mean value of the total stress is due solely to membrane stretching, the mean value of the total stress and the standard deviation can be expressed as

$$
\mu=\left(S_{\text {membrane }}\right)_{\text {Mean }}, \quad \sigma=1 / 2\left(S_{\text {bending }}\right)_{\text {RMS }} .
$$

For the case considered, the presented total stress mean static correction yielded fairly accurate stress ratios, as denoted in Table 4. All reduced modal fatigue estimates remained non-conservative relative to the results obtained from the physical DoF analysis.

\subsection{Pre-Buckled Regime}

Fatigue estimates for the room temperature condition indicated that the $\mathrm{B}$ and $\mathrm{BM}$ bases provided the most accurate fatigue estimates relative to estimates obtained from the physical DoFs analysis. The CBC and UBC bases did not provide improved stress response or fatigue life estimates. Therefore the analysis in the prebuckled elevated temperature regime is restricted to B and BM bases only.

\subsubsection{Stress Response and Fatigue Analysis}

The total stress PSDs at the clamped end in the pre-buckled regime for 146 and $164 \mathrm{~dB}$ loadings are shown in Figure 21 and Figure 22, respectively. Consistent with the room temperature results, results from the BM basis compare more favourably with the physical DoF solution than the bending modes only. The B basis tends to over-broaden the peaks corresponding to the higher modes and to under-predict their magnitudes. The same conclusions hold for the total stress PSDs at the quarter-span (not shown).

The fatigue life evaluated in the pre-buckled regime is shown for the clamped end and the quarter-span locations in Table 5. Since the $S-N$ curves for specific stress ratios resulting from the presence of compressive thermal loading where not 
In Proceedings of The Seventh International Conference on Computational Structures Technology, Topping, B.H.V. and Mota Soares, C.A., Eds., Civil-Comp Press, Stirling, United Kingdom, 2004.

available, all the presented estimates are based on the $S-N$ curve for $R=-1$. It is observed that even for the highest excitation level, where the pressure loading is dominant over the relatively small temperature increase, the presence of a constant thermal compression has a substantial effect and reduces fatigue life by two orders of magnitude relative to the room temperature fatigue life estimates in Table 1.

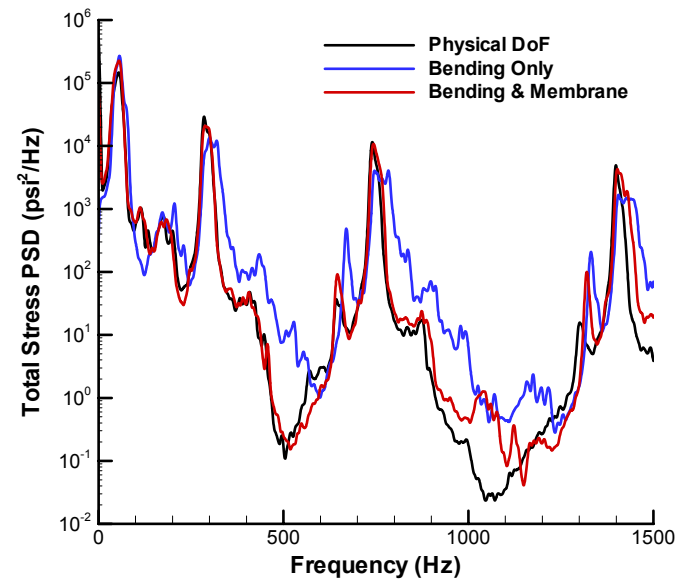

Figure 21: Total stress PSD at clamped end for $146 \mathrm{~dB}$ loading (pre-buckled).

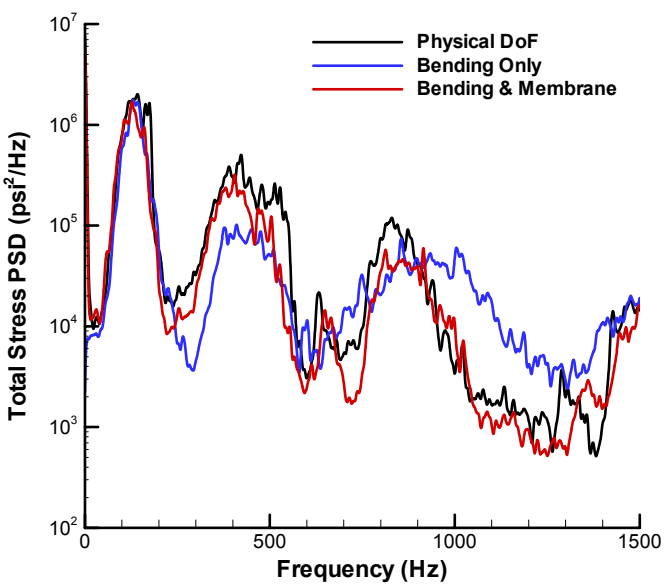

Figure 22: Total stress PSD at clamped end for $164 \mathrm{~dB}$ loading (pre-buckled).

\begin{tabular}{|c|c|c|c|c|c|}
\hline Location & OASPL $(\mathrm{dB})$ & Units & Physical DoF & B & BM \\
\hline \multirow{3}{*}{$\begin{array}{c}\text { Clamped } \\
\text { End }\end{array}$} & 146 & Years & 12.361 & 2.418 & 5.358 \\
\cline { 2 - 6 } & 152 & Hours & 221.81 & 324.341 & 260.573 \\
\cline { 2 - 6 } & 164 & Seconds & 0.948 & 35.86 & 59.462 \\
\hline \multirow{2}{*}{$\begin{array}{c}\text { Quarter- } \\
\text { Span }\end{array}$} & 146 & Years & $3.773 \times 10^{5}$ & $3.081 \times 10^{5}$ & $1.826 \times 10^{5}$ \\
\cline { 2 - 6 } & 152 & Years & 540.08 & 1146.36 & 624.29 \\
\cline { 2 - 6 } & 164 & Hours & 50.150 & 21.126 & 68.058 \\
\hline
\end{tabular}

Table 5: Fatigue life estimates for the pre-buckled regime $(R=-1)$.

\section{Conclusions}

The effect of modal basis selection on displacement response, stress response and fatigue life estimation using a nonlinear modal simulation was investigated. With regard to displacement and stress response, for the case considered, it was found that

- the bending and membrane modal basis offered the only accurate prediction of membrane displacement and the best prediction of bending, membrane and total stress,

- the bending modes only basis offered the second best approach as it did not produce anomalous behavior in the displacement PSDs, did not increase the size of the coupled set of modal equations, allowed for the largest integration time step of all bases, and did not have the added complication of identifying membrane modes or computing companion modes, 
In Proceedings of The Seventh International Conference on Computational Structures Technology, Topping, B.H.V. and Mota Soares, C.A., Eds., Civil-Comp Press, Stirling, United Kingdom, 2004.

- the $\mathrm{CBC}$ basis produced non-physical behavior in the membrane displacement PSDs, and therefore its use is not recommended,

- inclusion of mass normalized UBC modes required significantly smaller integration time steps than for any other bases considered; the problem is particularly severe for the static variation of companion modes.

With regard to fatigue life estimates, it was found for the case considered that

- all modal bases variants generally gave non-conservative estimates of fatigue life at the clamped end relative to that obtained through simulation in physical DoFs,

- the modal bases sometimes gave conservative estimates and sometimes gave non-conservative estimates of fatigue life at the quarter-span,

- overall, the B and BM bases gave the most accurate estimates of fatigue life, followed by the CBC basis; the UBC basis gave the least accurate estimates,

- accurate membrane stress modeling is important at all locations; the static membrane stress affects the stress ratio and consequently the selection of $S-N$ curve used for fatigue estimation,

- the B and CBC bases were incapable of accurate membrane stress modeling at certain locations and consequently yielded inaccurate stress ratios; a procedure was developed to estimate the static mean stress for such cases,

- all reduced order modal fatigue estimates at the clamped end remained nonconservative relative to the results obtained from the physical DoF analysis for $R \neq-1$.

\section{References}

[1] Mei, C., Dhainaut, J.M., Duan, B., Spottswood, S.M., and Wolfe, H.F., "Nonlinear random response of composite panels in an elevated thermal environment," Air Force Research Laboratory, Wright-Patterson Air Force Base, OH, AFRL-VA-WP-TR-2000-3049, October 2000.

[2] Przekop, A., "Nonlinear response and fatigue estimation of aerospace curved surface panels to combined acoustic and thermal loads," Ph.D. Dissertation, Old Dominion University, 2003.

[3] Przekop, A., Guo, X., Azzouz, M.S., and Mei, C., "Reinvestigation of nonlinear random response of shallow shells using finite element modal formulation," Proceedings of the 45th AIAA/ASME/ASCE/AHS/ASC Structures, Structural Dynamics and Materials Conference, AIAA-2004-1553, Palm Springs, CA, 2004.

[4] McEwan, M.I., Wright, J.R., Cooper, J.E., and Leung, Y.T., "A finite element/modal technique for nonlinear plate and stiffened panel response prediction," Proceedings of the 42nd AIAA/ASME/ASCE/AHS/ASC Structures, Structural Dynamics, and Materials Conference, AIAA-2001-1595, Seattle, WA, 2001.

[5] Muravyov, A.A. and Rizzi, S.A., "Determination of nonlinear stiffness with application to random vibration of geometrically nonlinear structures," Computers and Structures, Vol. 81, No. 15, pp. 1513-1523, 2003. 
In Proceedings of The Seventh International Conference on Computational Structures Technology, Topping, B.H.V. and Mota Soares, C.A., Eds., Civil-Comp Press, Stirling, United Kingdom, 2004.

[6] Rizzi, S.A. and Przekop, A., "The effect of basis selection on thermal-acoustic random response prediction using nonlinear modal simulation," Proceedings of the 45th AIAA/ASME/ASCE/AHS/ASC Structures, Structural Dynamics and Materials Conference, AIAA-2004-1554, Palm Springs, CA, 2004.

[7] Hollkamp, J.J., Gordon, R.W., and Spottswood, S.M., "Nonlinear sonic fatigue response prediction from finite element modal models: a comparison with experiments," Proceedings of the 44th AIAA/ASME/ASCE/AHS/ASC Structures, Structural Dynamics, and Materials Conference, AIAA-20031709, Norfolk, VA, 2003.

[8] Mignolet, M.P., Radu, A.G., and Gao, X., "Validation of reduced order modeling for the prediction of the response and fatigue life of panels subjected to thermo-acoustic effects," Structural Dynamics: Recent Advances, Proceedings of the 8th International Conference, Southampton, UK, 2003.

[9] Rizzi, S.A. and Muravyov, A.A., "Improved equivalent linearization implementations using nonlinear stiffness evaluation," NASA TM-2001210838, March 2001.

[10] Press, W.H., Teukolsky, S.A., Vetterling, W.T., and Flannery, B.P., "Numerical recipes, the art of scientific computing," CDROM v2.10, Cambridge University Press, 2002.

[11] Dowling, N.E., "Fatigue failure predictions for complicated strain-stress histories," Journal of Materials, Vol. 7, pp. 71-87, 1972.

[12] Matsuishi, M. and Endo, T., "Fatigue of metals subjected to varying stress," Japan Society of Mechanical Engineers, Fukuoka, Japan, March, 1968.

[13] Rychlik, I., "A new definition of the rainflow cycle counting method," International Journal of Fatigue, Vol. 9, No. 2, pp. 119-121, 1987.

[14] "WAFO - A Matlab toolbox for analysis of random waves and loads," Version 2.0.02, The WAFO Group, Lund Institute of Technology, Lund University, 2000.

[15] Miner, M.A., "Cumulative damage in fatigue," Trans. ASME, Journal of Applied Mechanics, Vol. 67, pp. A159-A164, 1945.

[16] Rizzi, S.A. and Muravyov, A.A., "Comparison of nonlinear random response using equivalent linearization and numerical simulation," Structural Dynamics: Recent Advances, Proceedings of the 7th International Conference, Vol. 2, pp. 833-846, Southampton, UK, 2000.

[17] Radu, A.G., Yang, B., Kim, K., and Mignolet, M.P., "Prediction of the dynamic response and fatigue life of panels subjected to thermo-acoustic loading," Proceedings of the 45th AIAA/ASME/ASCE/AHS/ASC Structures, Structural Dynamics and Materials Conference, AIAA-2004-1557, Palm Springs, CA, 2004.

[18] "Military handbook MIL-HDBK-5H: Metallic materials and elements for aerospace vehicle structures," Knovel Interactive Edition, 2003.

[19] Rizzi, S.A., "On the use of equivalent linearization for high-cycle fatigue analysis of geometrically nonlinear structures," Structural Dynamics: Recent Advances, Proceedings of the 8th International Conference, Southampton, UK, 2003. 